\title{
Safety of Low Dose Atracurium Added to Lidocaine, Bupivacaine and Hyaluronidase Mixture in Percaruncular Peribulbar Anesthesia for High Myopes Undergoing Phacoemulsification (A Randomized Controlled Trial)
}

\author{
MAHA M.A. MOSTAFA, M.Sc.*; NAZMY E. SEIF, M.D.*; MAHA M.I. YOUSSE, M.D.*; \\ MAHMOUD M. SOLIMAN, M.D.** and ASHRAF M. AMIN, M.D.* \\ The Departments of Anesthesia, Pain Management \& Surgical ICU* and Ophthalmology**, Faculty of Medicine, \\ Cairo University
}

\begin{abstract}
Background: The current study explored the safety of adding low dose atracurium to lidocaine, bupivacaine and hyaluronidase mixture in percaruncular peribulbar anesthesia for high myopes undergoing phacoemulsification.

Methods: 82 ASA-PS I-III patients scheduled for phacoemulsification with high myopia were enrolled in this randomized controlled double-blinded trial. The enrolled patients were randomly allocated to one of two groups. Group C $(n=41)$ received $2.5 \mathrm{ml}$ of lidocaine $2 \%, 2.5 \mathrm{ml}$ of bupivacaine $0.5 \%$ with hyaluronidase $15 \mathrm{IU} / \mathrm{ml}$ and $1 \mathrm{ml}$ normal saline, while patients in Group A $(n=41)$ received the same mixture with $5 \mathrm{mg}$ atracurium. Patients' hemodynamics, peripheral $\mathrm{O}_{2}$ saturation, occurrence of intraoperative pain and incidence of were recorded.

Results: There were no major complications in any of the 82 cases. The incidence of minor complications between both groups were comparative. Chemosis occurred in $12.2 \%$ of Group A and in $24.3 \%$ of Group C. Sub-conjunctival hemorrhage occurred in $4.9 \%$ of patients of both groups. Local hyperemia were only observed in Group A (7.3\%) with no statistical significance.
\end{abstract}

Conclusion: Adding $5 \mathrm{mg}$ atracurium to LA solution did not increase the incidence of complications in percaruncular block in high myopes.

Key Words: Lidocaine - Atracurium - Bupivacaine - Hyaluronidase - High myopes - Phacoemulsification.

\section{Introduction}

THERE are several regional anesthetic techniques available for phacoemulsification procedures and the choice depend on patient, surgical and operator

Correspondence to: Dr. Maha M.A. Mostafa, The Department of Anesthesia, Pain Management \& Surgical ICU, Faculty of Medicine, Cairo University factors [1]. Patients with axial myopia (axial length more than $26 \mathrm{~mm}$ ) have thin sclera, limited space between globe and orbit and out-pouching of the sclera (staphyloma). Staphylomata are more frequently encountered inferior to the posterior pole (increasing the risk of perforation following inferotemporal puncture in both peri- and retro-bulbar blocks) [2-5].

Single medial canthal peri-bulbar injection (percaruncular) may provide a safer alternative to inferotemporal peri-and retro-bulbar techniques for phacoemulsification procedures in myopic patients. The space between the medial orbital wall and the globe is comparable to that of inferotemporal approach and devoid of blood vessels. Moreover, myopic staphylomata are infrequently located on the nasal side of the globe $[2,5-8]$

The effect of Non-Depolarizing Neuromuscular Blockers (ND-NMB) on the inferotemporal periand retrobulbar block has been described in many studies. The studied ND-NMB were atracurium, cis atracurium, and vecuronium. According to those studies, the use of ND-NMB as adjuvant to inferotemporal peri-and retrobulbar block provide early onset of akinesia in absence of any adverse effects [9-15].

The current study aimed to explore effect of adding low dose atracurium to local anesthetic mixture on incidence of complications, hemodynamics and peripheral $\mathrm{O}_{2}$ saturation $\left(\mathrm{SpO}_{2}\right)$ in percaruncular peri-bulbar anesthesia for high myopes undergoing phacoemulsification. 


\section{Patients and Methods}

This was a single center parallel randomized controlled double-blinded trial conducted in Kasr Al-Ainy Hospital, Ophthalmology Surgical Theater, from May, 2015 to May, 2016.

After obtaining the Department of Anesthesia, Pain Management and Surgical ICU and Department of Ophthalmology Ethical Committee approbation, Cairo University Medical School approval (July, 2014) and informed consents from the patients, 91 American Society of Anesthesiologists' physical class (ASA-PS) I-III patients scheduled for phacoemulsification with high myopia (axial length $>26 \mathrm{~mm}$ ) were enrolled in the study.

Patients who were $<18$ or $>75$ years old, pregnant, ASA-PS >III, their axial length was $<26 \mathrm{~mm}$ or had contraindication to regional anesthesia (absolute contraindications: Patient refusal to participate in the study, local anesthetic allergy and infection/marked orbital inflammation or relative contraindications: Unable to lie flat for a sufficient length of time, confusion or psychiatric illness, communication difficulties, bleeding diathesis or taking anticoagulants, previous scleral buckling or space-occupying lesions within the orbit) were excluded from the study.

The enrolled patients were randomly allocated to one of two groups using computer-generated number and concealed using sequentially numbered, sealed opaque envelopes. Group C $(n=46)$ received $2.5 \mathrm{ml}$ of lidocaine $2 \%$ (lidocaine hydrochloride $2 \%$ pharmacell $20 \mathrm{ml}$, manufactured by Sigmatec Pharmaceutical Industries, 6 October city, Egypt for Pharmacell Company-Egypt), 2.5 $\mathrm{ml}$ of bupivacaine $0.5 \%$ (Sunnypivacaine $0.5 \% 20$ $\mathrm{ml}$ vial, Sunny Pharmaceutical, Badr City, Cairo, Egypt) with hyaluronidase $15 \mathrm{IU} / \mathrm{ml}$ (Omnidase 1500iu Injection, Sunways India Pvt Ltd, India. Diluted in 2 vial lidocaine $20 \mathrm{ml}$ resulting $37.5 \mathrm{IU} / \mathrm{ml}$ lidocaine and $93.7 / 2.5 \mathrm{ml}$ lidocaine or $15.6 \mathrm{IU} / \mathrm{ml}$ of the $6 \mathrm{ml}$ solution) and $1 \mathrm{ml}$ normal saline to make total volume of $6 \mathrm{ml}$, while patients in Group A $(\mathrm{n}=45)$ received $2.5 \mathrm{ml}$ of lidocaine $2 \%, 2.5 \mathrm{ml}$ of bupivacaine $0.5 \%$ with hyaluronidase $15 \mathrm{IU} / \mathrm{ml}$ and $5 \mathrm{mg}$ atracurium (Atracurium Hameln $10 \mathrm{mg} / \mathrm{ml}$ manufactured by Sunny Pharmaceutical, Badr City, Cairo, Egypt under license of Hameln Pharmaceuticals-Germany) in $1 \mathrm{ml}$ normal saline to make a total volume of $6 \mathrm{ml}$ from which the patient received $5-6 \mathrm{ml}$. Neither the administrator of the block nor the surgeon knew which drug mixture was given.

Pre-operatively, the axial length of the enrolled patients was measured by ultrasound biometry and the presence of staphyloma was identified by Bscan.

In the preparation room, the Intravenous (IV) cannula was placed. Anxious patients were given midazolam intravenously (titrated to response according to patient's age and associated medical condition).

In the operating room, standard monitoring of pulse oximetry, Electrocardiography (ECG) and noninvasive arterial blood pressure were commenced. The $\mathrm{O}_{2}$ was administered at $2 \mathrm{ml} /$ minutes by the nasal $\mathrm{O}_{2}$ cannula.

Benoxinate $0.4 \%$ eye drops (BENOX® $0.4 \%$ $10 \mathrm{ml}$ Manufactured by Egyptian Int. Pharmaceutical Industries Co. (E.I.P.I.CO.)-Egypt) were instilled in the eye to be operated upon three times separated by a one-minute interval.

While in a supine position, the patient was asked to look directly ahead focusing on a fixed point on the ceiling so that the eyes were in the neutral position. A medial canthus injection was given using a $25 \mathrm{G}, 25 \mathrm{~mm}$ needle under complete aseptic condition. The needle insertion point was just medial to the caruncle. While the needle was perpendicular to the face, it was introduced parallel to the medial orbital wall to $15-20 \mathrm{~mm}$ depth [5]

After negative aspiration, the already chosen local anesthetic mixture was injected slowly. If the tension was felt to rise in the globe during injection (the globe was palpated with one finger and the lids tension was tested frequently) the injection would be stopped. After injection, external compression with Honan balloon inflated to $20-30 \mathrm{~mm}$ $\mathrm{Hg}$ was applied for 10 minutes and was removed every 2 minutes to test akinesia and anesthesia [5]

The data were recorded by the administrator of the block who was blinded to which drug mixture was given. Blood pressure, heart rate (baseline, 5 minutes after local anesthetic injection, 5 minutes after the beginning of the operation) and peripheral $\mathrm{O}_{2}$ saturation $(\mathrm{SpO} 2)$ (baseline and 5 minutes after local anesthetic injection) were recorded.

Ocular Movement Score (OMS) was assessed every 2 minutes by asking the patient to move his/ her eye in four directions; up, down, medially and laterally and the movement in each direction is given a score from 0 to 2 as follows: Movement more than $2 \mathrm{~mm}$ was given a score of $2,1-2 \mathrm{~mm}$ movement was given a score of 1 and no movement was given a score of 0 . A total Score of 2 or less was considered adequate akinesia for surgery [8] 
If, after 10 minutes, the block was inadequate, a $3-4 \mathrm{ml}$ supplementation of lidocaine $2 \%$ by the same technique was given. If the block was still inadequate, the patient received either supplemental inferotemporal injection (if ultrasound excluded presence of posterior staphyloma), topical anesthesia, intravascular fentanyl 50mcg or general anesthesia according to the patient's condition. After adequate analgesia (loss of sensation to touch by a small cotton wool) and akinesia (OMS $\leq 2)$, the surgeon was allowed to start the surgery.

The occurrence of major complications (retrobulbar hemorrhage, globe penetration, optic nerve damage, local anesthetic toxicity) or minor complications (chemosis, subconjunctival hemorrhage, diplopia or/and local hyperemia) was recorded.

\section{Statistical analysis:}

Statistical analysis was carried out using SPlus Statistical Software (SPSS) for Windows (Version 20.0, SPSS Inc. Chicago, Illinois). All variables were tested for normality using Kolmogorov-Smirnov test; if the test was significant, non-normality was accepted. Otherwise doublechecking using graphs, skewness and kurtosis were required to confirm normality.

Continuous variables were described as mean \pm standard deviation when normality of distribution assumptions was satisfied. If not, it was presented as median and range. Categorical variables were presented as numbers and percentages. Wilcoxon Matched-Pair Signed-Rank was used to compare paired non-parametric data. Two-tailed unpaired student $t$-test was used to compare quantitative variables, and Fisher's exact test was used to compare qualitative variables. A $p$-value of $<0.05$ was accounted to be significant.

Based on a two-sided alpha of $0.05,95 \%$ power, and a clinically relevant difference in time of onset of akinesia at least 3 minutes, a minimum of 74 patients were needed for the study (MedCalc ${ }^{\circledR}$ version 12.7.1.0-64-bit).

\section{Results}

82 patients scheduled for phacoemulsification in Kasr Al-Ainy Hospital were enrolled in the current study and randomly allocated into two groups [Group A $(n=41)$ and Group C $(n=41)$ ] from May, 2015 to May, 2016.

As regards the demographic characteristics of both groups, there were no significant statistical difference (Table 1).
Table (1): Demographic characteristics

\begin{tabular}{llcc}
\hline & $\begin{array}{c}\text { Group A } \\
(\mathrm{N}=41)\end{array}$ & $\begin{array}{c}\text { Group C } \\
(\mathrm{N}=41)\end{array}$ & $\begin{array}{c}p- \\
\text { value }\end{array}$ \\
\hline Age (years) & $49.2 \pm 8.21$ & $52.3 \pm 9.32$ & 0.493 \\
$\begin{array}{l}\text { Gender n (\%): } \\
\quad \text { Female }\end{array}$ & & & \\
$\quad$ Male & $22(53.7)$ & $22(53.7)$ & 1 \\
Axial length (mm) & $19(46.3)$ & $19(46.3)$ & \\
Need for sedation n (\%) & $29.1 \pm 2.12$ & $29 \pm 2.28$ & 0.677 \\
Duration of the surgery (min.) & $11(26.8)$ & $12(29.3)$ & 0.806 \\
Posterior staphyloma n (\%) & $3(7.3)$ & $4(9.7)$ & 0.765 \\
ASA-PS n (\%): & & & \\
$\quad$ I & $19(46.3)$ & $17(41.5)$ & 0.656 \\
$\quad$ II & $20(48.8)$ & $18(43.9)$ & 0.658 \\
$\quad$ III & $2(4.9)$ & $6(14.6)$ & 0.264 \\
\hline
\end{tabular}

Numerical data were presented as mean \pm SD, categorical data were presented as frequency $(\%), p<0.05$ considered statistically significant.

There was no statistically significant deference regarding the hemodynamic changes between the two groups, furthermore there was no statistical significant difference between the hemodynamic readings inside each group (Table 2 ).

Table (2): Hemodynamic changes.

\begin{tabular}{llll}
\hline & $\begin{array}{c}\text { Group A } \\
(\mathrm{N}=41)\end{array}$ & $\begin{array}{c}\text { Group C } \\
(\mathrm{N}=41)\end{array}$ & $\begin{array}{c}p^{*} \\
\text { value }\end{array}$ \\
\hline$M A P:$ & & & \\
- Base line & $90.1 \pm 11.07$ & $92.7 \pm 12.92$ & 0.219 \\
- 5min. after LA injection & $89.7 \pm 10.57$ & $92.2 \pm 12.52$ & 0.408 \\
- 5min. after procedure onset & $89.7 \pm 11.30$ & $92.4 \pm 12.59$ & 0.503 \\
- At regaining full ocular movement & $89.9 \pm 10.97$ & $92.6 \pm 12.50$ & 0.345 \\
- $p \#$ & 0.276 & 0.359 & \\
HR: & & & \\
- Base line & & & \\
- 5min. after LA injection & $75.0 \pm 8.63$ & $74.6 \pm 8.86$ & 0.949 \\
- 5min. after procedure onset & $74.2 \pm 7.89$ & $74.2 \pm 8.40$ & 0.969 \\
- At regaining full ocular movement & $73.6 \pm 6.80$ & $73.2 \pm 7.40$ & 0.708 \\
• $p \#$ & 0.250 & 0.195 & \\
\hline
\end{tabular}

Numerical data were presented as mean $\pm \mathrm{SD}$

$p *<0.05$ was considered statistically significant when both groups were compared together.

$p \#<0.05$ was considered statistically significant when $5 \mathrm{~min}$. after onset of procedure reading compared to baseline reading within the same group.

$\mathrm{SpO}_{2}$ readings were recorded (on nasal $\mathrm{O}_{2}$ cannula) at baseline and 5 minutes after local anesthetic injection. There was no statistical significant deference in $\mathrm{SpO}_{2}$ readings between the two groups (Table 3 ).

Table (3): $\mathrm{SpO}_{2}$ changes.

\begin{tabular}{lccc}
\hline & $\begin{array}{c}\text { Group A } \\
(\mathrm{N}=41)\end{array}$ & $\begin{array}{c}\text { Group C } \\
(\mathrm{N}=41)\end{array}$ & $\begin{array}{c}p \text { - } \\
\text { value }\end{array}$ \\
\hline - Base line & $98.8 \pm 1.17$ & $98.8 \pm 1.11$ & 0.755 \\
- 5 minutes after local & $98.8 \pm 1.12$ & $98.7 \pm 1.02$ & 0.753 \\
$\quad$ anesthetic injection. & & & \\
\hline
\end{tabular}

Numerical data were presented as mean $\pm \mathrm{SD}, p<0.05$ considered statistically significant. 
Regarding the incidence of complications, there was no major complications in any of the 82 cases. As regard minor complications, there was no statistical significant difference in the incidence of minor complications between both groups $(p=$ 0.666) (Table 4).

Table (4): Incidence of complications.

\begin{tabular}{llll}
\hline & $\begin{array}{c}\text { Group A } \\
(\mathrm{N}=41)\end{array}$ & $\begin{array}{c}\text { Group C } \\
(\mathrm{N}=41)\end{array}$ & $\begin{array}{c}p- \\
\text { value }\end{array}$ \\
\hline Total No. of complications n (\%). & $10(24)$ & $12(29)$ & 0.666 \\
Chemosis n (\%). & $5(12)$ & $10(24)$ & 0.153 \\
Subconjunctival Hemorrhage n (\%). & $2(5)$ & $2(5)$ & 1 \\
Local hyperemia n (\%). & $3(7)$ & $0(0)$ & 0.241 \\
\hline
\end{tabular}

Categorical data were presented as frequency $(\%), p$-value $<0.05$ considered statistically significant.

Chemosis and sub-conjunctival hemorrhage were managed conservatively. Local hyperemia were only observed in Group A (3 cases) and were managed by I.V steroid. Local hyperemia resolved by the time of completion of the surgery.

\section{Discussion}

Due to the presence of staphylomas, myopic patients are at increased risk of globe perforation following inferotemporal punctures in both periand retro-bulbar blocks [2-5]. Because of that, available regional anesthetic techniques for phacoemulsification would be either topical, sub-Tenon's or medial canthal block. The use of topical anesthesia preserved to an experienced surgeon, uncomplicated surgery and cooperative patients [1]. It was observed that not many ophthalmic surgeons nor anesthetists (residents and senior registrars) are experienced with sub-Tenon's block in kasr alainy hospital. Medial canthal peribulbar (percaruncular) technique provide a good and familiar alternative for myopic patients.

While many studies demonstrated the effect of adding ND-NMB to peri-and retrobulbar regional block on achieving better akinesia, the current study demonstrated the effect of adding low dose atracurium to lidocaine, bupivacaine and hyaluronidase mixture on on incidence of complications, hemodynamics and peripheral $\mathrm{O}_{2}$ saturation $\left(\mathrm{SpO}_{2}\right)$ in percaruncular peri-bulbar anesthesia for high myopes undergoing phacoemulsification.

There were no statistically significant differences in peripheral oxygen saturation, mean blood pressure and heart rate values between Groups A and Group C during the study. This was comparative with Küçü kyavuz et al., [16] findings. Also the mean blood pressure and heart rate variability were not significant within each group. While other studies that tested the effect of ND-NMB did not comment on hemodynamic changes nor $\mathrm{SpO}_{2}$ changes $[10,12-15]$

Other studies that used ND-NMB as well as the current study did not report any major systemic or local complications related to the drug nor the used technique [10-15,17].

The incidence of chemosis was comparative between the 2 groups (12\% (5/41) in Group A and $24 \%$ (10/41) in Group C. Chemosis was not reported by other studies that used ND-NMB. This could be due to the use of techniques other than percaruncular injection in those studies [10-14,17,18].

Sub-conjunctival hemorrhage occurred in 4 cases $(2(4.9 \%)$ in each group). While A. Abdellatif et al., [12] reported Sub-conjunctival hemorrhage in $6(20 \%)$ patients in control and $8(27 \%)$ in rocuronium, this might be due to giving double injections from the start.

While chemosis and subconjunctival hemorrhage could be attributed to the used technique, we observed 3 cases of local hyperemia in Group A which was not reported in studies that used atracurium in ophthalmic regional blocks $[13,15,16]$. Local hyperemia managed by giving I.V steroid and was resolved at the time of completion of the procedure. The occurrence of local hyperemia might be due to local histamine release effect of atracurium [19].

In conclusion, adding $5 \mathrm{mg}$ atracurium to LA solution in the percaruncular block in myopic patients did not affect patients' hemodynamics nor $\mathrm{SpO}_{2}$ with low risk of drug-related complications.

\section{References}

1- KUMAR C.M., et al.: Local anaesthesia for ophthalmic surgery-new guidelines from the Royal College of Anaesthetists and the Royal College of Ophthalmologists. Eye, 26: 897-8, 2012.

2- VOHRA S.B. and GOOD P.A.: Altered globe dimensions of axial myopia as risk factors for penetrating ocular injury during peribulbar anaesthesia. Br. J. Anaesth., 85: 242-5, 2000.

3- EDGE R. and NAVON S.: Scleral perforation during retrobulbar and peribulbar anesthesia: Risk factors and outcome in 50000 consecutive injections. J. Cataract Refract. Surg., 25: 1237-44, 1999.

4- KUMAR C.: Orbital regional anesthesia: Complications and their prevention. Indian J. Ophthalmol.; 54: 77, 2006.

5- RIPART J., NOUVELLON E. and CHAUMERON A.: Regional anesthesia for eye surgery. Reg. Anesth. Pain Med., 30: 72-82, 2005 
6- ALLMAN K.G., McFADYEN J.G., ARMSTRONG J., STURROCK G.D. and WILSON I.H.: Comparison of articaine and bupivacaine/lidocaine for single medial canthus peribulbar anaesthesia. Br. J. Anaesth., 87: 5847, 2001 .

7- DERUDDRE S. and BENHAMOU D.: Medial canthus single-injection peribulbar anesthesia: A prospective randomized comparison with classic double-injection peribulbar anesthesia. Reg. Anesth. Pain Med., 30: 2559, 2005.

8- SAMIR A. and GABAL A.: Percaruncular single injection peribulbar anaesthesia in patients with axial myopia for phacoemulsification. Saudi J. Ophthalmol. Off. J. Saudi Ophthalmol. Soc., 26: 87-90, 2012.

9- ALLAN T.W.B.: Systemic spread of vecuronium following use in peribulbar regional anaesthesia. Anaesthesia, 56: 1018-9, 2008

10- GHANEM M.T. and TAWFEEK M.A.: Adding low dose rocuronium to local anesthetic mixture: Effect on quality of peribulbar blockade for vitreoretinal surgery. Egypt. J. Anaesth., 32: 201-5, 2016.

11-Z.K.: et al.: Effects of atracurium added to local anesthetics on akinesia in peribulbar block. Reg. Anesth. Pain Med., 27: 487-90, 2002.

12- ABDELLATIF A.A., EL-SHAHAWY M.A., AHMED A.I., ALMARAKBI W.A. and ALHASHEMI J.A.: Effects of local low-dose rocuronium on the quality of peribulbar anesthesia for cataract surgery. Saudi J. Anaesth., 5: 3604, 2011.

13- GODARZI M., et al.: Comparing the effect of using atracourium and cis-atracourium as adjuvant agents to the local anesthetic substance on peribulbar-induced akinesia. Acta Med. Iran., 49: 509-12, 2011.

14- AISSAOUI Y., BELYAMANI L. and DRISSI KAMILI N.: Effect of the addition of rocuronium to local anesthetics for peribulbar block. Acta Anaesthesiol. Belg., 61: 51-4, 2010.

15- EGHBAL M.H., TABEI H., TAREGH S.A. and RAZEGHINEJAD M.R.: The effect of addition of low dose atracurium to local anesthetic in retrobulbar block for cataract surgery. Middle East J. Anesthesiol., 20: 535-8, 2010.

16- KÜÇÜKYAVUZ Z. and ARICI M.K.: Effects of atracurium added to local anesthetics on akinesia in peribulbar block. Reg. Anesth. Pain Med., 27: 487-90, 2002.

17- ELMONAEM H.M.A., ELSHAHAT E., MOSTAFA A. and ARABY E.E.EL.: Effects Of Atracurium Added to Local Anesthetics on AkiniseiaIn Sub-Tenon's Block. Ain Shams J. Anesthesiol., 4: 35-47, 2011.

18- GHALI A.M. and EL-BTARNY A.M.: The effect on outcome of peribulbar anaesthesia in conjunction with general anesthesia for vitreoretinal surgery. Anaesthesia, 65: 249-53, 2010.

19- HUNTER J.M.: Histamine release and neuromuscular blocking drugs. Anaesthesia, 48: 561-3, 1993.

\section{كفاءة وسلامة إضافة جرعة منخفضة من عقار الآتراكيريه إلى الليدوكاين،

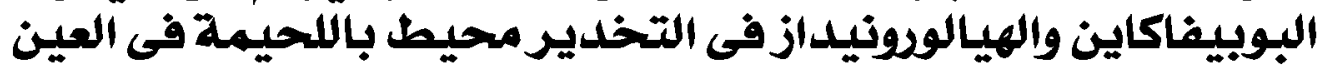

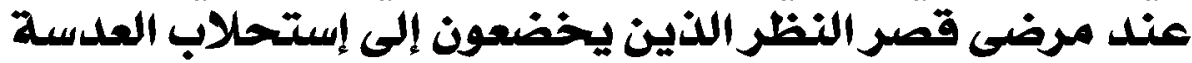

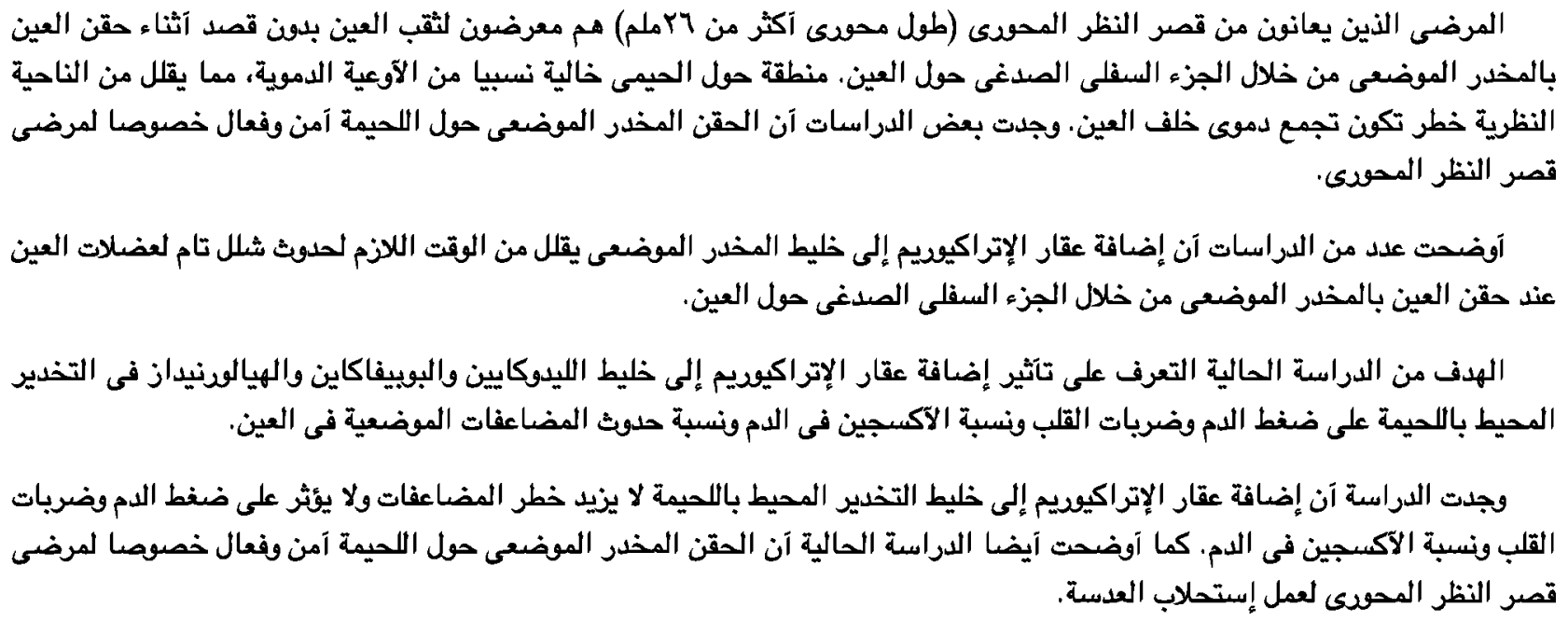

